\title{
p73 regulates primary cortical neurons metabolism: a global metabolic profile
}

Massimiliano Agostini ${ }^{1,2}$, Maria Victoria Niklison-Chirou ${ }^{1 \#}$, Margherita Maria AnnicchiaricoPetruzzelli $^{3}$, Sandro Grelli ${ }^{2}$ Nicola Di Daniele ${ }^{4}$, Ilias Pestlikis ${ }^{2}$, Richard A. Knight ${ }^{1}$, Gerry Melino $^{1,2 *}$ and Alessandro Rufini ${ }^{5 \S}$

${ }^{1}$ Medical Research Council, Toxicology Unit, Leicester University, Leicester LE1 9HN, UK.

${ }^{2}$ Department of Experimental Medicine and Surgery, University of Rome "Tor Vergata", 00133 Rome, Italy.

${ }^{3}$ Biochemistry Laboratory IDI-IRCC, c/o Department of Experimental Medicine and Surgery, ${ }^{4}$ Department of Systems Medicine, Nephrology and Hypertension Unit, "Tor Vergata" University Hospital, Rome, Italy.

${ }^{5}$ Department of Cancer Studies, CRUK Leicester Cancer Centre, University of Leicester, Leicester, LE2 7LX, UK.

Correspondence:

${ }^{\S}$ A.R. Department of Cancer Studies, CRUK Leicester Cancer Centre, University of Leicester, Leicester, LE2 7LX, UK. Email: ar230@le.ac.uk; Tel +44 116252 3127; Fax: +44 1162231855

*G.M. Medical Research Council, Toxicology Unit, Leicester University, Leicester LE1 9HN, UK. Email: gm89@le.ac.uk Tel +44 116252 5564, Fax +44 (0) 1162525616

Current Address:

\# Blizard Institute of Cell and Molecular Science, Barts and the London School of Medicine and Dentistry, Queen Mary University of London, London, E1 2AT, UK

\section{RUNNING TITLE: p73 regulates cortical neurons metabolism}

Abbreviations: TAp73, Transcriptionally active p73; $\triangle \mathrm{Np} 73$, amino truncated p73; DMED, Dulbecco minimal essential medium; FBS, foetal bovine serum; Ct, cycle; GC, Gas chromatography; MS, Mass Spectrometry; LC, Liquid chromatography; DMED, Dulbecco minimal essential medium; FBS, foetal bovine serum; DIV, day in vitro; ATP5A, Mitochondrial membrane ATP synthase $\mathrm{F}(1) \mathrm{F}(0)$ ATP synthase or Complex V; FCCP, Carbonyl cyanide 4(trifluoromethoxy) phenylhydrazone; UQCRC2, ubiquinol-cytochrome c reductase core protein II; MTCO1, mitochondrially encoded cytochrome c oxidase I; SDHB, succinate dehydrogenase complex, subunit B, iron sulphur; NDUFB8, NADH Dehydrogenase (Ubiquinone) 1 Beta Subcomplex, 8;

\section{Acknowledgments}

We would like to thank Dr Ivano Amelio for helpful comments and suggestions. This work has been supported by the Medical Research Council, UK; grants from Associazione Italiana per la Ricerca contro il Cancro (AIRC): AIRC 2014 IG15653 (to G.M.), AIRC 5xmille MCO9979 (to G.M.), Fondazione Roma malattie Non trasmissibili Cronico-Degenerative (NCDS-201300000334) Grant (to G.M.).

The authors declare that they have no conflict of interest. 


\section{Abstract (193 words)}

The transcription factor $\mathrm{p} 73$ has been demonstrated to play a significant role in survival and differentiation of neuronal stem cells. In this report, by employing comprehensive metabolic profile and mitochondrial bioenergetics analysis, we have explored the metabolic alterations in cortical neurons isolated from p73 N-terminal isoforms specific knockout animals. We found that loss of the TAp73 or $\triangle \mathrm{Np} 73$ triggers selective biochemical changes. In particular, p73 isoforms regulate sphingolipid and phospholipid biochemical pathways- signaling. Indeed, sphinganine and sphingosine levels were reduced in p73 null cortical neurons and decrease levels of several membrane phospholipids were also observed. Moreover, in line with the complexity associated with p73 functions, loss of the TAp73 seems to increase glycolysis while on the contrary loss $\Delta \mathrm{Np} 73$ isoform reduces glucose metabolism, indicating an isoform-specific differential effect on glycolysis. These changes in glycolytic flux were not reflected by parallel alterations of mitochondrial respiration, as only a slight increase of mitochondrial maximal respiration was observed in p73 null cortical neurons. Overall, our findings reinforce the key role of p73 in regulating cellular metabolism and point out that p73 exerts its functions in neuronal biology at least partially through the regulation of metabolic pathways.

Keywords: p73, p53 family, metabolism, neurons, sphingolipids 


\section{Introduction}

The transcription factor p73 [1-3], a member of the p53-family [4-6], [7,8] exerts its role through the regulation of several biological processes including cell survival [9-11], differentiation [12-14], cellular metabolism [15-20], and autophagy [21]. This pleiotropic role of p73 is mainly due to the fact that the tp73 gene is expressed in numerous isoforms, including two main $\mathrm{N}$ terminal isoforms: a full-length protein named TAp73, and a shorter, $\mathrm{N}$-terminal truncated $\Delta \mathrm{Np} 73$ isoform. It is generally accepted that the TA isoforms are transcriptionally active while the $\Delta \mathrm{N}$ isoforms act as dominant negative and therefore transcriptionally inactive [1]. Notwithstanding these differences, mice generated by genetic deletion of the whole tp73 gene (p73-/-) [22] or selective N-terminal isoforms (TAp73-/- and $\Delta \mathrm{Np} 73-/-$ ) [23,24] all show postnatal alterations affecting the central nervous system (CNS). Indeed, the hippocampal dysgenesis observed in p73/- and TAp73-/- mice manifests around 6 days of age, in agreement with the reported increase in TAp73 expression during neuronal maturation [25,26]. On the other hand, the neuronal loss and reduced cognitive and motor functions affecting $\Delta \mathrm{Np} 73-/-$ mice starts to be significantly evident in aged (26-27 months old) mice [24]. Overall, these findings indicate that p73 isoform are required for proper CNS development and neuronal homeostasis throughout the animal lifespan, although the downstream molecular pathways implicated appear complex and remain to be fully elucidated. Clearly, since p73 is a transcription factor, the phenotype observed in p73-/- mice is in part linked to regulation of gene expression. Indeed, several genes that are involved in neuronal biology, such as, SOX-2 [27], Hey-2 [28], TRIM32 [29] and p75NTR [30], are either directly or indirectly regulated by TAp73 [31-35]. In addition, TAp73 controls the expression of miR-34a, suggesting that microRNAs [36,26] also participate in the multifunctional role of p73 in neurons, such as differentiation [26]. Growing findings indicate that $\mathrm{p} 73$ proteins also regulate cellular metabolism [37-40], and we have recently shown that during neuronal differentiation, TAp73 promotes the expression of glutaminase 2 (GLS2), an enzyme that deaminates glutamine to produce glutamate, the most common excitatory neurotransmitter [41]. This latter discovery indicates that p73mediated regulation of metabolism is an additional player in the regulation of neuronal function.

In this report, performing global metabolic profiling on cortical neurons isolated from isoform specific knockout mice, we widened our previous observations and investigated TAp73 and $\Delta \mathrm{Np} 73$ regulation of cellular metabolism in neuronal cells. We describe significant changes in few, but key, metabolites that point to GABA, and ceramide signaling as potential targets regulated by both p73 isoforms. Moreover, consistent with the often intricate crosstalk between p73 isoforms, selective loss of the TAp73 and $\Delta$ Np73 leads to opposite outcomes on glycolysis and metabolism of neurotransmitters, but has a convergent effect on regulation of lipid signaling molecules.

\section{Results}

\section{Global metabolic profile of cortical neurons derived from TAp73-/- and $\Delta \mathrm{Np} 73-/-$ mice}

p73 proteins play a key role in neuronal differentiation and survival [42]. Recently we have also shown that p73 regulates cellular metabolism [37,15,18]. With regard to CNS, our previous data indicate that cortical neurons isolated from TAp73-/- mice appeared to have reduced levels of GABA, while levels of the inhibitory neurotransmitter glycine were reduced in $\Delta \mathrm{Np} 73-/-$ cells 
[41]. To investigate whether these changes belonged to a wider metabolic rewiring caused by loss of p73 expression, a global metabolic profile was carried out [43], in cortical neurons derived from TAp73-/- and $\Delta$ Np73-/- mice after 7 days of in vitro culture (DIV7). 11 metabolites out of 217 were statistically $(\mathrm{p}<0.05)$ different in cortical neurons of both genotypes when compared to the control neurons (Table 1 and 2). Moreover, we found that levels of 14 and 28 metabolites were nearly-significant $(0.05<\mathrm{p}<0.10)$ different in TAp73-/- and $\Delta \mathrm{Np} 73-/$ - respectively when compared to control cells. Overall, these findings suggest that p73 $\mathrm{N}$-terminal isoforms regulate cellular metabolism in cortical neurons.

\section{Bioenergetic Glucese metabolism is potentially affected by the loss of p73}

Glycolysis is the main energetic source for neurons and is essential neuronal cells survival [44] [45] [46] (Fig 1A). Although not statistically significant, several biochemicals relating to glucose utilization, including the glycolytic intermediates 2-phosphoglycerate and phosphoenolpyruvate and the end product lactate, were increased in TAp73-/- cortical neurons. These increments were accompanied by elevated intracellular glucose levels, suggesting that glucose uptake may be increased in these cells (Fig 1B), and overall identifying a potential inhibitory role for TAp73 in the regulation of glycolysis. Conversely, glucose and glycolytic intermediates were slightly reduced in $\Delta \mathrm{Np} 73-/$ - neurons. Within the cell a second possible fate of glucose is fueling the Pentose Phosphate Pathway (PPP), leading to biosynthesis of the 5-carbon sugar ribose 5phosphate (Fig 2A). As shown in figure 2B, levels of ribose 5-phosphate were statistically reduced in cortical neurons derived from $\Delta \mathrm{Np} 73-/-$ mice, while in TAp73-/- counterparts the reduction failed to reach the significance.

The changes observed in glucose metabolism prompted us to investigate whether the loss of p73 could affect bioenergetics metabolism. Then, because mitochondrial bioenergetics is compromised by the loss of TAp73 [18], we asked whether loss of p73 isoforms could also affect mitochondrial function in cortical neurons. To do so, we took advantage of the Seahorse Extracellular Flux Analyzer that allows measurement of the oxygen consumption rate (OCR), an indicator of mitochondrial activity, and performed a mitochondrial stress test (Fig 3A). We did not observe major alterations, although DIV7 cortical neurons derived from p73-/- mice show a slight, but significant, reduction in basal respiration when compared to cortical neurons derived from WT mice (Fig 3B). Moreover, the maximal respiratory capacity, measured following addition of the proton ionophore uncoupling agent FCCP was higher in p73-/- cortical neurons (Fig 3B). Although statistically not significant, the same trend was also observed in cortical neurons derived from both genotypes (Fig S1 and S2). However, no differences between p73-/- and WT cortical neurons were observed in the expression levels of the several subunits of the ETC, namely ATP5A, UQCRC2, MTCO1, SDHB and NDUF0B9, as assessed using western blotting (Fig 3C and Fig S3). Overall these data indicates that p73 has a minimal effect on the regulation of mitochondrial activity in neuronal cells.

\section{Fatty acid synthesis and membrane remodelling in the absence of p73 isoforms}

We have recently reported that, during differentiation of wild type (WT) cortical neurons, the levels of long chain fatty acids (LCFA) and lysolipids increase, whereas the intracellular content of medium chain fatty acids (MCFA) decreases [43]. This suggests that changes in lipid metabolism sustain the membrane remodeling that occurs during neuronal differentiation. Interestingly, our metabolic profile shows that in $\triangle \mathrm{Np} 73-/-$ cortical neurons at DIV 7 LCFA are decreased as compared to WT cells (Fig 4 and table 2). In addition, as shown in figure 5 
membrane phospholipids, especially phosphocholine and phosphoethanolamine, were significantly reduced in $\Delta \mathrm{Np} 73-/-$ neurons. A trend towards reduced phospholipid levels was also observed in cortical neurons derived from TAp73-/-, although it failed to reach statistical significance (Fig 5B).

Overall, these results confirm previous findings showing that TAp73 is involved in the regulation of phospholipids biosynthesis [38].

\section{Sphingolipid levels are reduced in $\mathbf{p 7 3}$ deficient cortical neurons}

The sphingolipid metabolic pathway produces the cellular membrane component sphingomyelin and the signaling molecule ceramide (Fig 6A), which is necessary for the proper differentiation of neuronal cells al least in part, acting as signaling molecule downstream of the p75NTR in hippocampal neurons [47,48]. Sphinganine and sphingosine, the ceramide precursor and degradation products, respectively, are progressively elevated in differentiating cortical neurons, reflecting a sustained rate of sphingolipid metabolism.[43]. Notably, in the absence of either $\mathrm{TAp} 73$ or $\Delta \mathrm{Np} 73$, these molecules were decreased, with a more dramatic effect in $\Delta \mathrm{Np} 73-/-$ cells (Fig 6B). Despite our analysis failed to directly detect ceramide, the changes in its metabolites might suggest that altered biosynthesis of these molecules could be partially responsible for the developmental defect and the aggravated neurodegeneration observed in the CNS of p73 deficient animals [49].

\section{Discussion}

The p53 family which is composed by the transcription factors p53 [50,51], p63 [52,53] and p73 play a key role in regulating cellular metabolism [54-56]. In particular, with a role in regulating gene expression, p73 has been demonstrated to play a significant role in neuronal cell biology, including survival and differentiation of stem cells [57]. To gain insight into the molecular mechanism by which $\mathrm{p} 73$ proteins regulate neuronal function a global metabolic profiling in cortical neurons was carried out. Here, we show that the steady-state levels of several metabolites are altered following the loss of p73 isoforms in DIV7 cortical neurons. Although the changes in metabolic profiles are subtle between genotypes, the data supports a role for p73 in regulating the differentiation of cortical neurons and points to GABA and ceramide signaling as potential targets regulated by $\mathrm{p} 73$ isoforms. Consistent with the complexity associated with p73 function, loss of the TAp73 and $\triangle \mathrm{Np} 73$ isoforms have differential effects on glycolysis and neurotransmitter metabolism, but triggers similar effects on lipid signaling molecules.

Lipids are the most abundant compound present in the brain (REF). More importantly, changes in lipid composition are associated with several neurological and psychiatric disorders [58]. In particular, alterations of myelin biogenesis have widely documented links to structural and functional abnormalities, including axonal and neuronal degeneration, ataxia and tremor [59]. Interestingly, p73-/- mice show impairments in the peripheral nervous system with reduced thermal sensitivity, axon number, and myelin thickness [60]. Therefore, the decrease in sphinganine, sphingosine and steraoyl sphingomyelin is found in TAp73-/- and $\Delta \mathrm{Np} 73-/$ - cortical neurons may indicate that $\mathrm{p} 73$ isoforms regulate myelin biogenesis also in oligodendrocytes and Schwann cells. Even though this possibility should be experimentally tested, we would like to speculate that the reduction of myelin thickness observed in p73-/- mice could be in part explained by a reduction in the biosynthesis of myelin in oligodendrocytes and Schwann cells in absence of p73 isoforms. Indeed, we have recently shown that TAp73 induces biosynthesis of membrane 
lipids in osteosarcoma cell line [38], supporting p73's role as regulator of lipids metabolism in different cellular context.

However, to determine whether these changes reflect persistent alterations of cellular metabolism, time course comparisons between WT and p73-/- neuronal cells at multiple time points to evaluate either global metabolism or selected metabolic pathways are warranted in future studies, supported by flux analysis of isotopic labelled compounds. In addition, it would be worth investigating the metabolic changes under pathological conditions, such as neurodegenerative disorders. Overall, the findings presented in this report strengthen the recent experimental evidences that $\mathrm{p} 73$ isoforms play an essential role in regulating cellular metabolism and contribute to our understanding of the phenotypes observed in knock-out mice.

\section{Materials and Methods}

\section{Mice}

Mice were bred and subjected to listed procedures under the Project Licence PPL 40/3442 released from the Home Office. p73 full $\mathrm{KO}$ mice (p73-/-) were generated and genotyped as previously described [22]. TAp73 KO mice (TAp73-/-) and $\triangle \mathrm{Np} 73 \mathrm{KO}$ mice were generated and genotyped as previously described [23,24]. Wild type (WT), heterozygous (Het) and homozygous (-/-) mice for each genetic background were created by intercrossing Het mice. Offspring were genotyped by PCR analysis as previously described [22-24]

\section{Cortical neurons preparation and treatment}

Primary cortical neuronal were prepared from E17.5 embryos as previously described [43]. Briefly, cortices were harvested and cut into small pieces. Tissue was incubated with $1 \times$ Trypsin (Invitrogen, UK) for 10 minutes at $37{ }^{\circ} \mathrm{C}$. After washing with Neurobasal medium (Invitrogen,

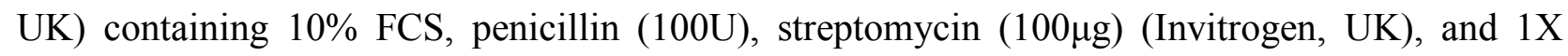
Glutamax (Invitrogen, UK), the tissue was resuspended by gentle pipetting. Cells were then counted using an hemocytometer, diluted to the appropriate concentration and then plated in aforementioned medium on poly-D-lysine-coated plates. After $1 \mathrm{~h}$, medium was replaced with growth medium (Neurobasal medium (Invitrogen, UK) containing B27 supplement (Invitrogen, $\mathrm{UK}$ ), penicillin (100U), streptomycin $(100 \mu \mathrm{g})$ (Invitrogen), and 1X Glutamax (Invitrogen, UK)) and maintained in culture for 7 days before being subjected to experimental procedures.

\section{Global metabolic profiling}

Cortical neurons were harvested at DIV7 and were immediately stored at $-80^{\circ} \mathrm{C}$. Samples were extracted and prepared for analysis using Metabolon's standard solvent extraction method (Metabolon, Inc. NC, USA). The sample preparation process was carried out as previously described [15]. Briefly, the protein fraction was removed by using a proprietary series of organic and aqueous extraction solutions. Then, the resulting extract was divided into two fractions; one for analysis by liquid chromatography (LC) and one for analysis by gas chromatography (GC). Each sample was first frozen and dried under vacuum. Samples were then processed for the appropriate instrument, either LC/MS or GC/MS. Instrument variability was determined by calculating the median relative standard deviation (RSD) for the internal standards that were added to each sample prior to injection into the mass spectrometers. Overall process variability was determined by calculating the median RSD for all endogenous metabolites (i.e., non-instrument 
standards) present in $100 \%$ of the Client Matrix samples, which are technical replicates of pooled samples. Following normalization to total protein determined by Bradford assay, log transformation and imputation with minimum observed values was performed for each compound.

\section{Extracellular flux (XF) analysis.}

Cortical neurons were seeded in XF 24-well cell culture microplate (Seahorse Bioscience, USA) in quintuplicate at $3 \times 10^{5}$ cells/well in $1 \mathrm{ml}$ growth medium and then incubated at $37^{\circ} \mathrm{C}$ in $5 \% \mathrm{CO}_{2}$. Assays were initiated, by removing the growth medium from each well and replacing it with fresh assay medium pre-warmed to $37^{\circ} \mathrm{C}$. Oxygen Consumption Rate (OCR) was measured simultaneously for 3-5 min to establish a baseline rate. After the baseline measurement, 75-90 $\mu 1$ of a testing agent (Oligomycin, FCCP and Rotenone) was injected into each well to reach the desired final working concentration. Generally, two to three baseline rate and two or more response rate (after compound addition) measurements were taken, and the average of two baseline rate or response rate readings was used for data analysis. The values of OCR levels were normalized to protein content.

\section{Western Blot}

Proteins were extracted from DIV7 cortical neurons with RIPA buffer containing protease inhibitor cocktail (Roche, UK). Protein concentration was determined using a Bradford dye-based spectrophotometry assay (Biorad, UK). Total protein was subjected to SDS-PAGE followed by immunoblotting with the indicated antibodies at the recommended dilutions. The following antibodies were used: MitoProfile ${ }^{\circledR}$ Total OXPHOS Rodent WB Antibody Cocktail (mouse, 1:250, Abcam, UK), $\beta$-Tubulin (rabbit, 1:1000, Santa Cruz, UK).

\section{Statistical Analysis}

All results are expressed as means \pm s.d. $\mathrm{p}<0.05$ was considered significant. In the metabolic profiling, Welch's two-sample t-tests were used to identify biochemicals that differed significantly between experimental groups. Statistical analysis was performed using GraphPad Prism 6.

\section{References}

1. Dotsch V, Bernassola F, Coutandin D, Candi E, Melino G (2010) p63 and p73, the ancestors of p53. Cold Spring Harbor perspectives in biology 2 (9):a004887. doi:10.1101/cshperspect.a004887 2. Gebel J, Luh LM, Coutandin D, Osterburg C, Lohr F, Schafer B, Frombach AS, Sumyk M, Buchner L, Krojer T, Salah E, Mathea S, Guntert P, Knapp S, Dotsch V (2016) Mechanism of TAp73 inhibition by DeltaNp63 and structural basis of p63/p73 hetero-tetramerization. Cell Death Differ 23 (12):1930-1940. doi:10.1038/cdd.2016.83

3. Chillemi G, Kehrloesser S, Bernassola F, Desideri A, Dotsch V, Levine AJ, Melino G (2016) Structural Evolution and Dynamics of the p53 Proteins. Cold Spring Harb Perspect Med. doi:10.1101/cshperspect.a028308

4. Amelio I, Melino G (2015) The p53 family and the hypoxia-inducible factors (HIFs): determinants of cancer progression. Trends Biochem Sci 40 (8):425-434. doi:10.1016/j.tibs.2015.04.007

5. Charni M, Aloni-Grinstein R, Molchadsky A, Rotter V (2016) p53 on the crossroad between regeneration and cancer. Cell Death Differ. doi:10.1038/cdd.2016.117

6. D'Abramo M, Besker N, Desideri A, Levine AJ, Melino G, Chillemi G (2016) The p53 tetramer shows an induced-fit interaction of the C-terminal domain with the DNA-binding domain. Oncogene 35 (25):3272-3281. doi:10.1038/onc.2015.388 
7. Amelio I, Inoue S, Markert EK, Levine AJ, Knight RA, Mak TW, Melino G (2015) TAp73 opposes tumor angiogenesis by promoting hypoxia-inducible factor 1alpha degradation. Proc Natl Acad Sci U S A 112 (1):226-231. doi:10.1073/pnas.1410609111

8. Kehrloesser S, Osterburg C, Tuppi M, Schafer B, Vousden KH, Dotsch V (2016) Intrinsic aggregation propensity of the p63 and p73 TI domains correlates with p53R175H interaction and suggests further significance of aggregation events in the p53 family. Cell death and differentiation 23 (12):1952-1960. doi:10.1038/cdd.2016.75

9. Melino G, Bernassola F, Ranalli M, Yee K, Zong WX, Corazzari M, Knight RA, Green DR, Thompson C, Vousden KH (2004) p73 Induces apoptosis via PUMA transactivation and Bax mitochondrial translocation. The Journal of biological chemistry 279 (9):8076-8083. doi:10.1074/jbc.M307469200

10. Ozaki T, Hosoda M, Miyazaki K, Hayashi S, Watanabe K, Nakagawa T, Nakagawara A (2005) Functional implication of p73 protein stability in neuronal cell survival and death. Cancer letters 228 (1-2):29-35. doi:10.1016/j.canlet.2004.12.050

11. Zhou X, Hao Q, Zhang Q, Liao JM, Ke JW, Liao P, Cao B, Lu H (2015) Ribosomal proteins L11 and L5 activate TAp73 by overcoming MDM2 inhibition. Cell death and differentiation 22 (5):755-766. doi:10.1038/cdd.2014.167

12. De Laurenzi V, Raschella G, Barcaroli D, Annicchiarico-Petruzzelli M, Ranalli M, Catani MV, Tanno B, Costanzo A, Levrero M, Melino G (2000) Induction of neuronal differentiation by p73 in a neuroblastoma cell line. The Journal of biological chemistry 275 (20):15226-15231

13. Billon N, Terrinoni A, Jolicoeur C, McCarthy A, Richardson WD, Melino G, Raff M (2004) Roles for p53 and p73 during oligodendrocyte development. Development 131 (6):1211-1220. doi:10.1242/dev.01035

14. Fernandez-Alonso R, Martin-Lopez M, Gonzalez-Cano L, Garcia S, Castrillo F, Diez-Prieto I, Fernandez-Corona A, Lorenzo-Marcos ME, Li X, Claesson-Welsh L, Marques MM, Marin MC (2015) p73 is required for endothelial cell differentiation, migration and the formation of vascular networks regulating VEGF and TGFbeta signaling. Cell Death Differ 22 (8):1287-1299. doi:10.1038/cdd.2014.214

15. Agostini M, Annicchiarico-Petruzzelli M, Melino G, Rufini A (2016) Metabolic pathways regulated by TAp73 in response to oxidative stress. Oncotarget. doi:10.18632/oncotarget.8935

16. He Z, Agostini M, Liu H, Melino G, Simon HU (2015) p73 regulates basal and starvationinduced liver metabolism in vivo. Oncotarget 6 (32):33178-33190. doi:10.18632/oncotarget.5090

17. Amelio I, Markert EK, Rufini A, Antonov AV, Sayan BS, Tucci P, Agostini M, Mineo TC, Levine AJ, Melino G (2013) p73 regulates serine biosynthesis in cancer. Oncogene. doi:10.1038/onc.2013.456

18. Rufini A, Niklison-Chirou MV, Inoue S, Tomasini R, Harris IS, Marino A, Federici M, Dinsdale D, Knight RA, Melino G, Mak TW (2012) TAp73 depletion accelerates aging through metabolic dysregulation. Genes Dev 26 (18):2009-2014. doi:10.1101/gad.197640.112

19. Sharif T, Ahn DG, Liu RZ, Pringle E, Martell E, Dai C, Nunokawa A, Kwak M, Clements D, Murphy JP, Dean C, Marcato P, McCormick C, Godbout R, Gujar SA, Lee PW (2016) The $\mathrm{NAD}(+)$ salvage pathway modulates cancer cell viability via p73. Cell Death Differ 23 (4):669680. doi:10.1038/cdd.2015.134

20. Lee P, Hock AK, Vousden KH, Cheung EC (2015) p53- and p73-independent activation of TIGAR expression in vivo. Cell Death Dis 6:e1842. doi:10.1038/cddis.2015.205

21. He Z, Liu H, Agostini M, Yousefi S, Perren A, Tschan MP, Mak TW, Melino G, Simon HU (2013) p73 regulates autophagy and hepatocellular lipid metabolism through a transcriptional activation of the ATG5 gene. Cell death and differentiation 20 (10):1415-1424. doi: $10.1038 /$ cdd.2013.104

22. Yang A, Walker N, Bronson R, Kaghad M, Oosterwegel M, Bonnin J, Vagner C, Bonnet H, Dikkes P, Sharpe A, McKeon F, Caput D (2000) p73-deficient mice have neurological, pheromonal and inflammatory defects but lack spontaneous tumours. Nature 404 (6773):99-103. doi: $10.1038 / 35003607$ 
23. Tomasini R, Tsuchihara K, Wilhelm M, Fujitani M, Rufini A, Cheung CC, Khan F, ItieYouten A, Wakeham A, Tsao MS, Iovanna JL, Squire J, Jurisica I, Kaplan D, Melino G, Jurisicova A, Mak TW (2008) TAp73 knockout shows genomic instability with infertility and tumor suppressor functions. Genes \& development 22 (19):2677-2691. doi:10.1101/gad.1695308 24. Wilhelm MT, Rufini A, Wetzel MK, Tsuchihara K, Inoue S, Tomasini R, Itie-Youten A, Wakeham A, Arsenian-Henriksson M, Melino G, Kaplan DR, Miller FD, Mak TW (2010) Isoform-specific p73 knockout mice reveal a novel role for delta Np73 in the DNA damage response pathway. Genes \& development 24 (6):549-560. doi:10.1101/gad.1873910

25. Grespi F, Amelio I, Tucci P, Annicchiarico-Petruzzelli M, Melino G (2012) Tissue-specific expression of p73 C-terminal isoforms in mice. Cell Cycle 11 (23):4474-4483. doi: $10.4161 /$ cc. 22787

26. Agostini M, Tucci P, Killick R, Candi E, Sayan BS, Rivetti di Val Cervo P, Nicotera P, McKeon F, Knight RA, Mak TW, Melino G (2011) Neuronal differentiation by TAp73 is mediated by microRNA-34a regulation of synaptic protein targets. Proceedings of the National Academy of Sciences of the United States of America 108 (52):21093-21098. doi:10.1073/pnas.1112061109

27. Favaro R, Valotta M, Ferri AL, Latorre E, Mariani J, Giachino C, Lancini C, Tosetti V, Ottolenghi S, Taylor V, Nicolis SK (2009) Hippocampal development and neural stem cell maintenance require Sox2-dependent regulation of Shh. Nature neuroscience 12 (10):1248-1256. doi: $10.1038 / \mathrm{nn} .2397$

28. Sakamoto M, Hirata H, Ohtsuka T, Bessho Y, Kageyama R (2003) The basic helix-loop-helix genes Hesr1/Hey1 and Hesr2/Hey2 regulate maintenance of neural precursor cells in the brain. The Journal of biological chemistry 278 (45):44808-44815. doi:10.1074/jbc.M300448200

29. Hillje AL, Pavlou MA, Beckmann E, Worlitzer MM, Bahnassawy L, Lewejohann L, Palm T, Schwamborn JC (2013) TRIM32-dependent transcription in adult neural progenitor cells regulates neuronal differentiation. Cell death \& disease 4:e976. doi:10.1038/cddis.2013.487

30. Hennigan A, O'Callaghan RM, Kelly AM (2007) Neurotrophins and their receptors: roles in plasticity, neurodegeneration and neuroprotection. Biochemical Society transactions $35(\mathrm{Pt}$ 2):424-427. doi:10.1042/BST0350424

31. Fujitani M, Cancino GI, Dugani CB, Weaver IC, Gauthier-Fisher A, Paquin A, Mak TW, Wojtowicz MJ, Miller FD, Kaplan DR (2010) TAp73 acts via the bHLH Hey2 to promote longterm maintenance of neural precursors. Current biology : CB 20 (22):2058-2065. doi:10.1016/j.cub.2010.10.029

32. Alexandrova EM, Talos F, Moll UM (2013) p73 is dispensable for commitment to neural stem cell fate, but is essential for neural stem cell maintenance and for blocking premature differentiation. Cell death and differentiation 20 (2):368. doi:10.1038/cdd.2012.134

33. Gonzalez-Cano L, Herreros-Villanueva M, Fernandez-Alonso R, Ayuso-Sacido A, Meyer G, Garcia-Verdugo JM, Silva A, Marques MM, Marin MC (2010) p73 deficiency results in impaired self renewal and premature neuronal differentiation of mouse neural progenitors independently of p53. Cell death \& disease 1:e109. doi:10.1038/cddis.2010.87

34. Gonzalez-Cano L, Hillje AL, Fuertes-Alvarez S, Marques MM, Blanch A, Ian RW, Irwin MS, Schwamborn JC, Marin MC (2013) Regulatory feedback loop between TP73 and TRIM32. Cell death \& disease 4:e704. doi:10.1038/cddis.2013.224

35. Agostini M, Tucci P, Chen H, Knight RA, Bano D, Nicotera P, McKeon F, Melino G (2010) p73 regulates maintenance of neural stem cell. Biochemical and biophysical research communications 403 (1):13-17. doi:10.1016/j.bbrc.2010.10.087

36. Mollinari C, Racaniello M, Berry A, Pieri M, de Stefano MC, Cardinale A, Zona C, Cirulli F, Garaci E, Merlo D (2015) miR-34a regulates cell proliferation, morphology and function of newborn neurons resulting in improved behavioural outcomes. Cell Death Dis 6:e1622. doi:10.1038/cddis.2014.589

37. Agostini M, Niklison-Chirou MV, Catani MV, Knight RA, Melino G, Rufini A (2014) TAp73 promotes anti-senescence-anabolism not proliferation. Aging 6 (11):921-930 
38. Amelio I, Antonov AA, Catani MV, Massoud R, Bernassola F, Knight RA, Melino G, Rufini A (2014) TAp73 promotes anabolism. Oncotarget 5 (24):12820-12934. doi:10.18632/oncotarget.2667

39. Du W, Jiang P, Mancuso A, Stonestrom A, Brewer MD, Minn AJ, Mak TW, Wu M, Yang X (2013) TAp73 enhances the pentose phosphate pathway and supports cell proliferation. Nat Cell Biol 15 (8):991-1000. doi:10.1038/ncb2789

40. Jiang P, Du W, Yang X (2013) A critical role of glucose-6-phosphate dehydrogenase in TAp73-mediated cell proliferation. Cell Cycle 12 (24):3720-3726. doi:10.4161/cc.27267

41. Velletri T, Romeo F, Tucci P, Peschiaroli A, Annicchiarico-Petruzzelli M, Niklison-Chirou MV, Amelio I, Knight RA, Mak TW, Melino G, Agostini M (2013) GLS2 is transcriptionally regulated by $\mathrm{p} 73$ and contributes to neuronal differentiation. Cell cycle 12 (22)

42. Niklison-Chirou MV, Killick R, Knight RA, Nicotera P, Melino G, Agostini M (2015) How Does p73 Cause Neuronal Defects? Mol Neurobiol. doi:10.1007/s12035-015-9381-1

43. Agostini M, Romeo F, Inoue S, Niklison-Chirou MV, Elia AJ, Dinsdale D, Morone N, Knight RA, Mak TW, Melino G (2016) Metabolic reprogramming during neuronal differentiation. Cell Death Differ. doi:10.1038/cdd.2016.36

44. Nehlig A, Coles JA (2007) Cellular pathways of energy metabolism in the brain: is glucose used by neurons or astrocytes? Glia 55 (12):1238-1250. doi:10.1002/glia.20376

45. Bolanos JP, Almeida A, Moncada S (2010) Glycolysis: a bioenergetic or a survival pathway? Trends in biochemical sciences 35 (3):145-149. doi:10.1016/j.tibs.2009.10.006

46. Ivanov AI, Malkov AE, Waseem T, Mukhtarov M, Buldakova S, Gubkina O, Zilberter M, Zilberter Y (2014) Glycolysis and oxidative phosphorylation in neurons and astrocytes during network activity in hippocampal slices. Journal of cerebral blood flow and metabolism : official journal of the International Society of Cerebral Blood Flow and Metabolism 34 (3):397-407. doi:10.1038/jcbfm.2013.222

47. van Echten-Deckert G, Herget T (2006) Sphingolipid metabolism in neural cells. Biochimica et biophysica acta 1758 (12):1978-1994. doi:10.1016/j.bbamem.2006.06.009

48. Brann AB, Scott R, Neuberger Y, Abulafia D, Boldin S, Fainzilber M, Futerman AH (1999) Ceramide signaling downstream of the p75 neurotrophin receptor mediates the effects of nerve growth factor on outgrowth of cultured hippocampal neurons. J Neurosci 19 (19):8199-8206

49. Mencarelli C, Martinez-Martinez P (2013) Ceramide function in the brain: when a slight tilt is enough. Cellular and molecular life sciences : CMLS 70 (2):181-203. doi:10.1007/s00018-0121038-X

50. Clausse V, Goloudina AR, Uyanik B, Kochetkova EY, Richaud S, Fedorova OA, Hammann A, Bardou M, Barlev NA, Garrido C, Demidov ON (2016) Wee1 inhibition potentiates Wip1dependent p53-negative tumor cell death during chemotherapy. Cell death \& disease 7:e2195. doi:10.1038/cddis.2016.96

51. Hall AE, Lu WT, Godfrey JD, Antonov AV, Paicu C, Moxon S, Dalmay T, Wilczynska A, Muller PA, Bushell M (2016) The cytoskeleton adaptor protein ankyrin-1 is upregulated by p53 following DNA damage and alters cell migration. Cell death \& disease 7:e2184. doi:10.1038/cddis.2016.91

52. Melino G, Memmi EM, Pelicci PG, Bernassola F (2015) Maintaining epithelial stemness with p63. Science signaling 8 (387):re9. doi:10.1126/scisignal.aaa1033

53. Memmi EM, Sanarico AG, Giacobbe A, Peschiaroli A, Frezza V, Cicalese A, Pisati F, Tosoni D, Zhou H, Tonon G, Antonov A, Melino G, Pelicci PG, Bernassola F (2015) p63 Sustains selfrenewal of mammary cancer stem cells through regulation of Sonic Hedgehog signaling. Proceedings of the National Academy of Sciences of the United States of America 112 (11):34993504. doi:10.1073/pnas.1500762112

54. Napoli M, Flores ER (2016) The p53 family orchestrates the regulation of metabolism: physiological regulation and implications for cancer therapy. British journal of cancer. doi:10.1038/bjc.2016.384

55. Viticchie G, Agostini M, Lena AM, Mancini M, Zhou H, Zolla L, Dinsdale D, Saintigny G, Melino G, Candi E (2015) p63 supports aerobic respiration through hexokinase II. Proceedings of 
the National Academy of Sciences of the United States of America 112 (37):11577-11582. doi:10.1073/pnas.1508871112

56. Li X, Zhao Y, Xia Q, Zheng L, Liu L, Zhao B, Shi J (2016) Nuclear translocation of annexin 1 following oxygen-glucose deprivation-reperfusion induces apoptosis by regulating Bid expression via p53 binding. Cell death \& disease 7 (9):e2356. doi:10.1038/cddis.2016.259

57. Niklison-Chirou MV, Killick R, Knight RA, Nicotera P, Melino G, Agostini M (2016) How Does p73 Cause Neuronal Defects? Molecular neurobiology 53 (7):4509-4520. doi:10.1007/s12035-015-9381-1

58. Lauwers E, Goodchild R, Verstreken P (2016) Membrane Lipids in Presynaptic Function and Disease. Neuron 90 (1):11-25. doi:10.1016/j.neuron.2016.02.033

59. Schmitt S, Castelvetri LC, Simons M (2015) Metabolism and functions of lipids in myelin. Biochimica et biophysica acta 1851 (8):999-1005. doi:10.1016/j.bbalip.2014.12.016

60. Niklison-Chirou MV, Steinert JR, Agostini M, Knight RA, Dinsdale D, Cattaneo A, Mak TW, Melino G (2013) TAp73 knockout mice show morphological and functional nervous system defects associated with loss of p75 neurotrophin receptor. Proceedings of the National Academy of Sciences of the United States of America 110 (47):18952-18957. doi:10.1073/pnas.1221172110 
Table 1. Statistical summary of biochemicals statistically or nearly statistically altered in TAp73-/- and $\Delta$ Np73-/- cortical neurons.

Table 2. Heat map of the global metabolic profile.

\section{Figure legends}

Figure 1: Glycolytic pathway in DIV7 cortical neurons derived from TAp73-/- and $\Delta \mathrm{Np} 73$-/mice. A) Schematic representation of the glycolytic pathway. B) DIV7 cortical neurons were harvested and levels of the indicated metabolites were assessed as described in material and methods section. Welch's Two Sample $t$-tests were used to identify biochemicals that differed significantly between experimental groups ( $n=5-6$ for each group). To note the robust increase in intracellular levels of glucose in TAp73-/- mice and the opposite decrease in $\Delta \mathrm{Np} 73-/-$ cells.

Figure 2: Pentose Phosphate Pathway (PPP) in DIV7 cortical neurons derived from TAp73/- and $\Delta$ Np73-/- mice. A) Schematic representation of the PPP. The PPP is one of the main source of reductive NADPH in cells and the final product ribose-5-phosphate provides the sugar moiety in the biosynthesis of nucleotides. B) DIV7 cortical neurons were harvested and levels of the indicated metabolites were assessed as described in material and methods section. Welch's Two Sample $t$-tests were used to identify biochemicals that differed significantly between experimental groups ( $n=5-6$ for each group). Ribose-5-phopshate levels were significantly reduced in $\Delta \mathrm{Np} 73$ /- cortical neurons.

Figure 3: Mitochondrial bioenergetics analysis of cortical neurons derived from WT and p73-/- mice. A) Real-time analysis of Oxygen Consumption Rate (OCR) in cortical neurons isolated from p73-/- mice and heterozygous controls (Het). ATP synthase inhibitor oligomicyn, mitochondrial uncoupler FCCP and mitochondrial complex I inhibitor rotenone were injected sequentially at the indicated time points into each well after baseline rate measurement. A representative experiment of 4 independent is shown. (B) Basal respiration and Maximal respiration (right). Each group is shown as a \% of baseline (measurement before oligomycin injection). Values are mean \pm SD (WT $n=1, p 73-/-n=2$; Each point, $n=5$ technical replicates). (C) Western blot analysis showing expression levels of protein markers of the different complexes of the electron transport chain in DIV7 cortical neurons from WT and p73-/- mice. Assay was performed with MitoProfile Total OXPHOS and tubulin was used as loading control. Right panel, densitometric analysis of the indicated subunit of the different complexes of the electron transport chain (WT/Het $n=4$ and p73-/- $n=4)$.

Figure 4: Cortical neurons derived from $\Delta \mathrm{Np} 73$-/- mice show a reduced fatty acid synthesis. A) DIV7 cortical neurons were harvested and levels of the indicated fatty acids were measured in the described metabolomics profiling. Note the decreased levels of LCFA in $\triangle$ Np73-/- neurons. Welch's Two Sample $t$-tests were used to identify biochemicals that differed significantly between experimental groups ( $n=5-6$ for each group). EFA= Essential Fatty Acid; MCFA= Medium Chain Fatty Acid; LCFA= Long Chain Fatty Acid

Figure 5: Membrane phospholipid metabolism. A) Schematic representation of membrane phospholipid pathway. B) A decrease in several phospholipids was observed in both TAp73-/- and $\Delta$ Np73-/- DIV7 cortical neurons. Welch's Two Sample $t$-tests were used to identify biochemicals that differed significantly between experimental groups ( $n=5-6$ for each group).

Figure 6: Sphingosine and ceramide metabolism. A) Schematic representation of the sphingolipid pathway, which leads to the biosynthesis of ceramide and sphingomyelin. B) DIV7 cortical neurons isolated from TAp73-/- and $\triangle \mathrm{Np} 73$-/- mice showed decrease levels of metabolites 
belonging to the sphingolipid pathway, suggested altered biosynthesis of ceramide and sphingomyelin.. Welch's Two Sample $t$-tests were used to identify significantly different biochemicals ( $n=5-6$ for each group).

Supplementary Figure 1: Mitochondrial respiration analysis of cortical neurons derived from WT and TAp73-/- mice. A) Real-time analysis of Oxygen Consumption Rate (OCR) in cortical neurons. ATP synthase inhibitor oligomicyn, mitochondrial uncoupler FCCP and mitochondrial complex I inhibitor rotenone were injected sequentially at the indicated time points into each well after baseline rate measurement. A representative experiment of 2 independent is shown. (B) Basal respiration and Maximal respiration (right). Each group is shown as a $\%$ of baseline (measurement before oligomycin injection). Values are mean \pm SD (WT $n=1$ TAp73-/$\mathrm{n}=2$; Each point, $\mathrm{n}=5$ technical replicates).

Supplementary Figure 2: Mitochondrial respiration analysis of cortical neurons derived from control (Het) and $\Delta \mathbf{N p 7 3 - / - ~ m i c e . ~ A ) ~ R e a l - t i m e ~ a n a l y s i s ~ o f ~ O x y g e n ~ C o n s u m p t i o n ~ R a t e ~}$ (OCR) in cortical neurons. ATP synthase inhibitor oligomicyn, mitochondrial uncoupler FCCP and mitochondrial complex I inhibitor rotenone were injected sequentially at the indicated time points into each well after baseline rate measurement. A representative experiment of 2 independent is shown. (B) Basal respiration and Maximal respiration (right). Each group is shown as a $\%$ of baseline (measurement before oligomycin injection). Values are mean \pm SD (Het $n=1$ $\Delta \mathrm{Np} 73-/-\mathrm{n}=2$; Each point, $\mathrm{n}=5$ technical replicates).

Supplementary Figure 3: Western blot analysis showing expression levels of protein markers of the different complexes of the electron transport chain in DIV7 cortical neurons from WT and p73-/- mice. Assay was performed with MitoProfile Total OXPHOS and tubulin was used as loading control. 


\begin{tabular}{c|c|c|c|c}
\hline & $\begin{array}{c}\text { Total number of } \\
\text { biochemicals with } \\
p \leq 0.05\end{array}$ & $\begin{array}{c}\text { Biochemicals }(\uparrow \downarrow) \\
p \leq 0.05\end{array}$ & $\begin{array}{c}\text { Total number of } \\
\text { biochemicals with } \\
0.05<p<0.10\end{array}$ & $\begin{array}{c}\text { Biochemicals }(\uparrow \downarrow) \\
0.05<p<0.10\end{array}$ \\
\hline$\frac{\text { TAp73-/- }}{\text { WT }}$ & 11 & $3 \mid 8$ & 14 & $2 \mid 12$ \\
\hline$\frac{\Delta \text { Np73-/- }}{\text { WT }}$ & 11 & $1 \mid 10$ & 28 & $1 \mid 27$ \\
\hline
\end{tabular}

Table 1. Altered biochemical in TAp73-/- and DNp73-/- cortical neurons. The total number of significant ( $p$-values $\leq 0.05$ ) or nearly-significant $(0.05<p<0.10)$ altered metabolites are reported. Red indicates up-regulated biochemicals and green indicates down-regulated compounds. 
A B
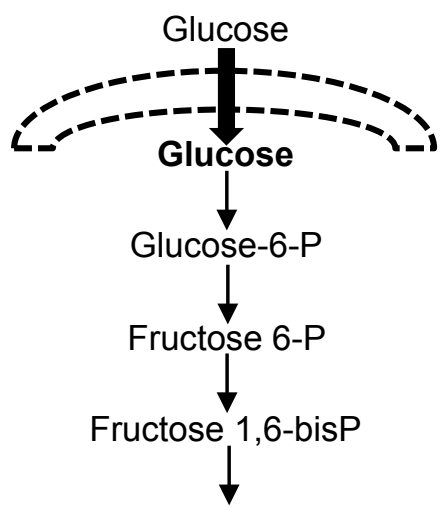

Glyceraldehyde 3-P

1,3-bisphosphoglycerate

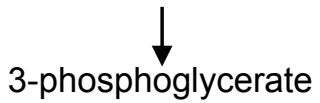

2-phosphoglycerate

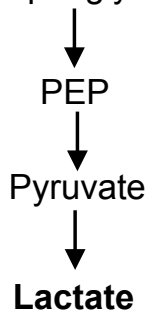

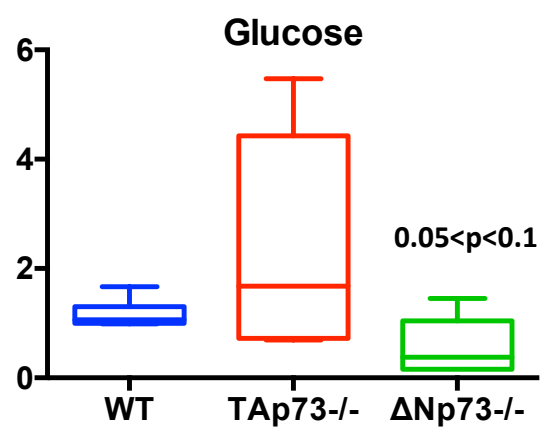
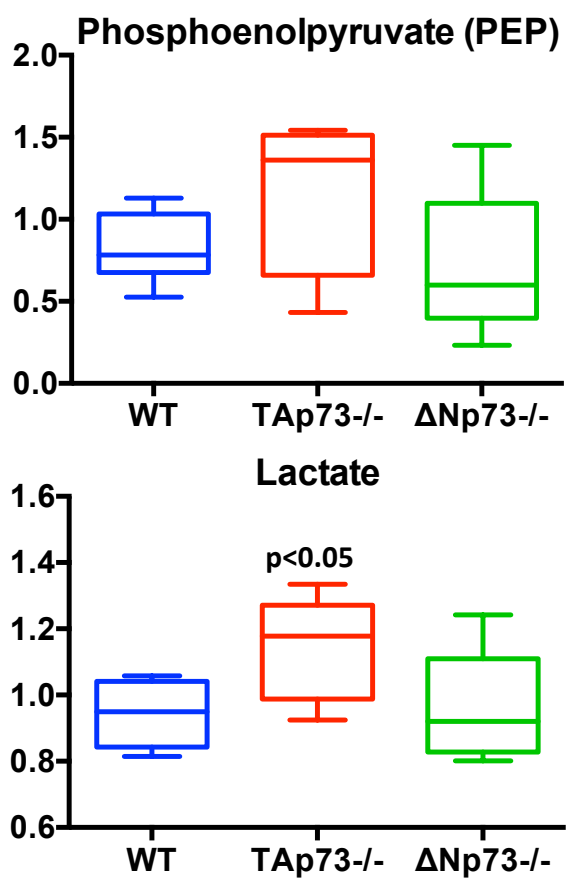
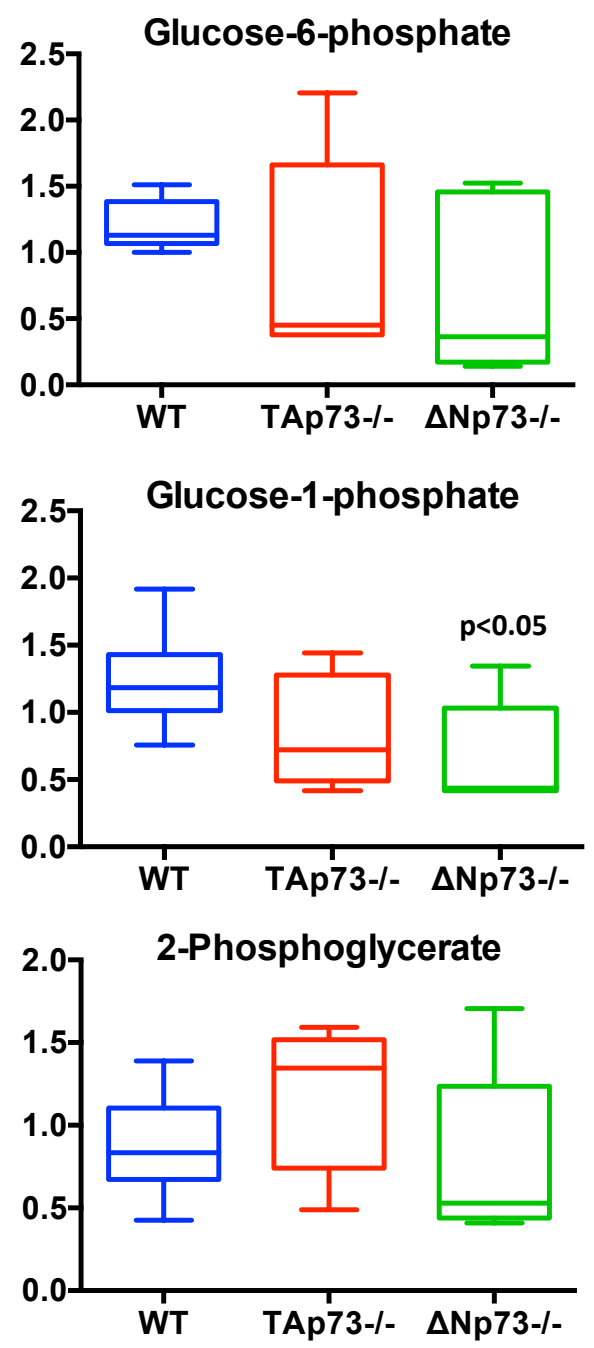
A

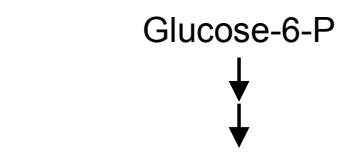

6-phosphogluconolactone

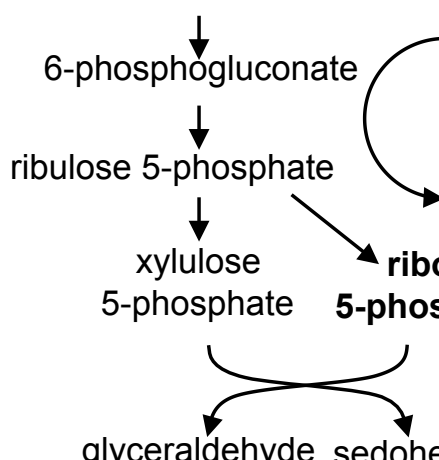

glyceraldehyde sedoheptulose

3-phosphate 7-phosphate

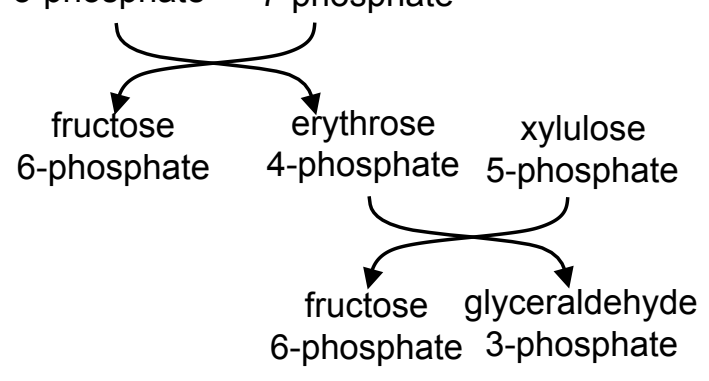

B

reducing equivalents
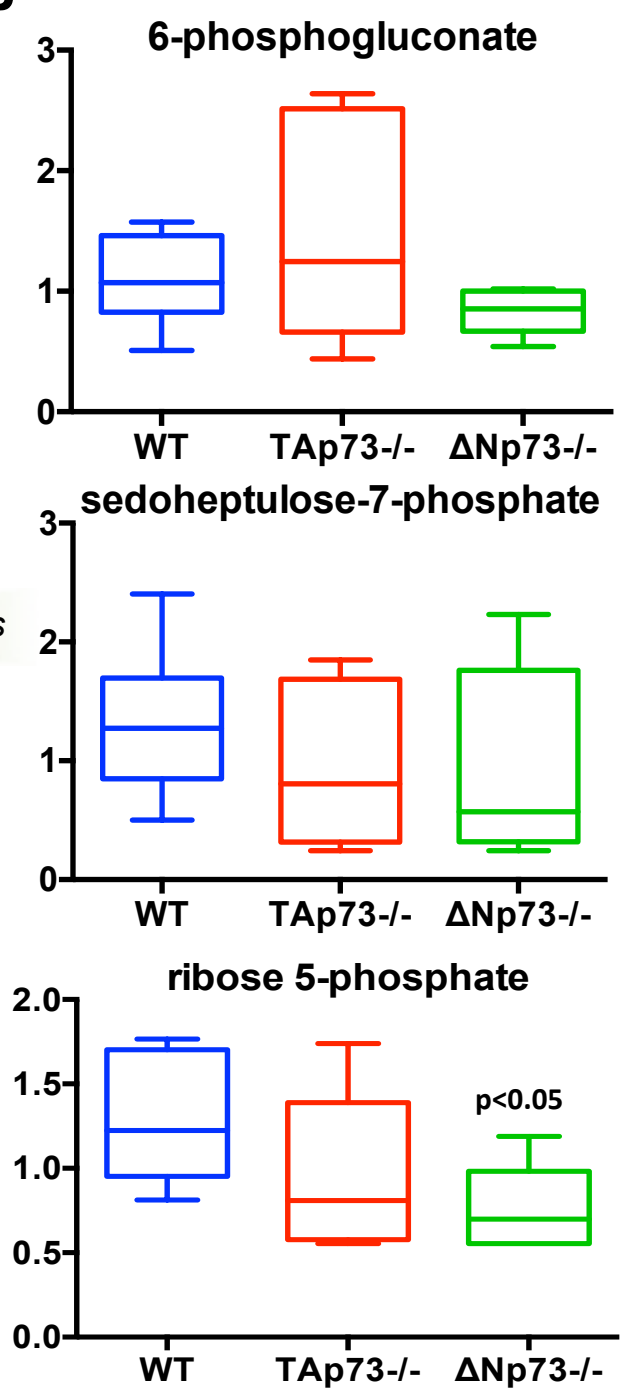


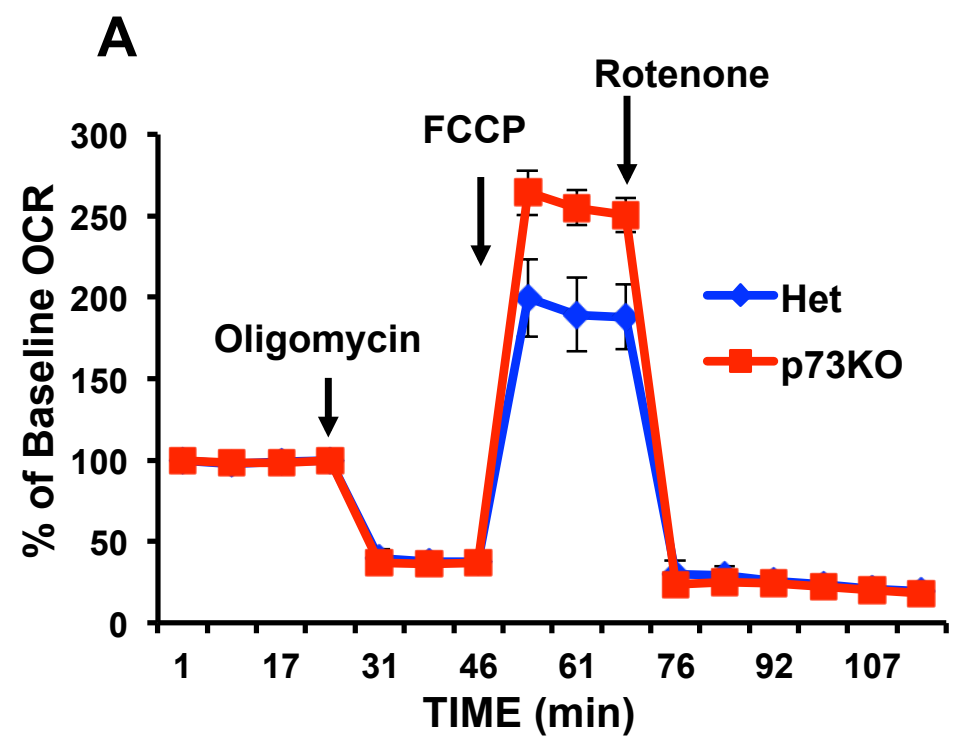

B

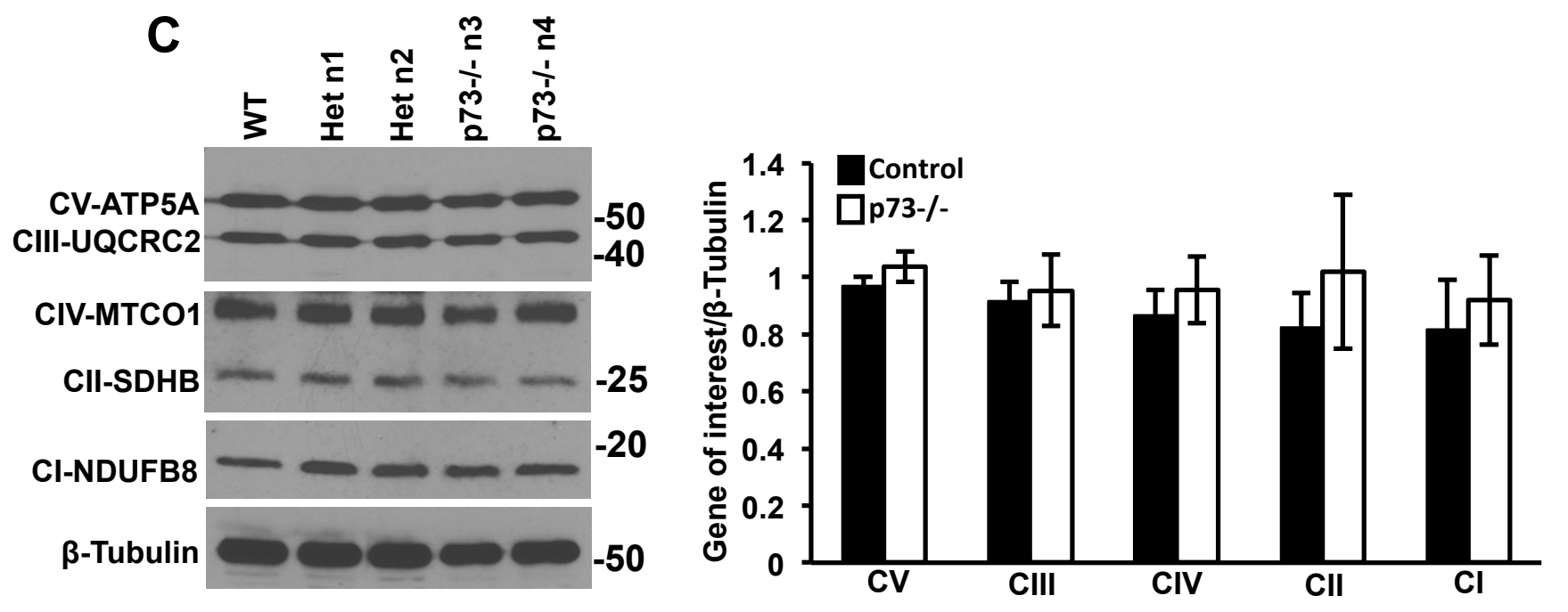


A
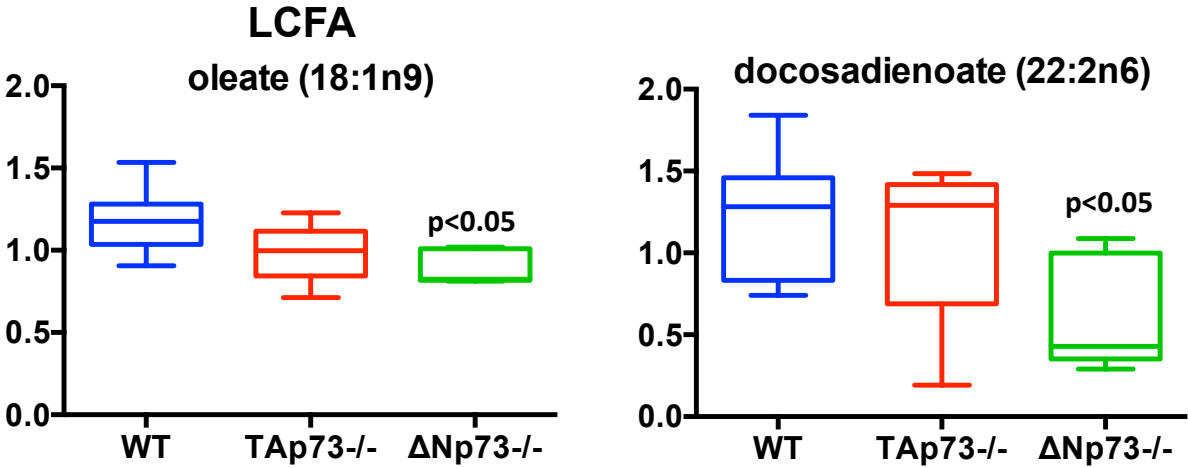

EFA

docosapentaenoate (n6 DPA; 22:5n6)

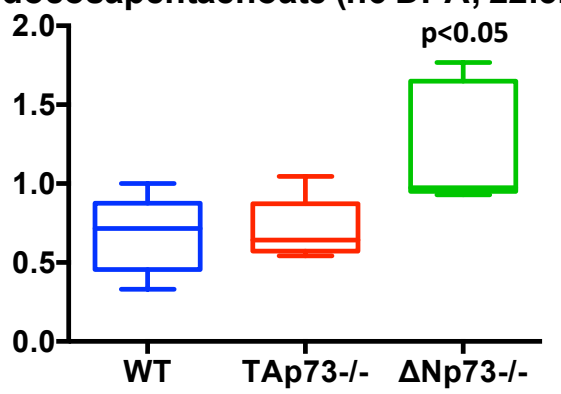

MCFA
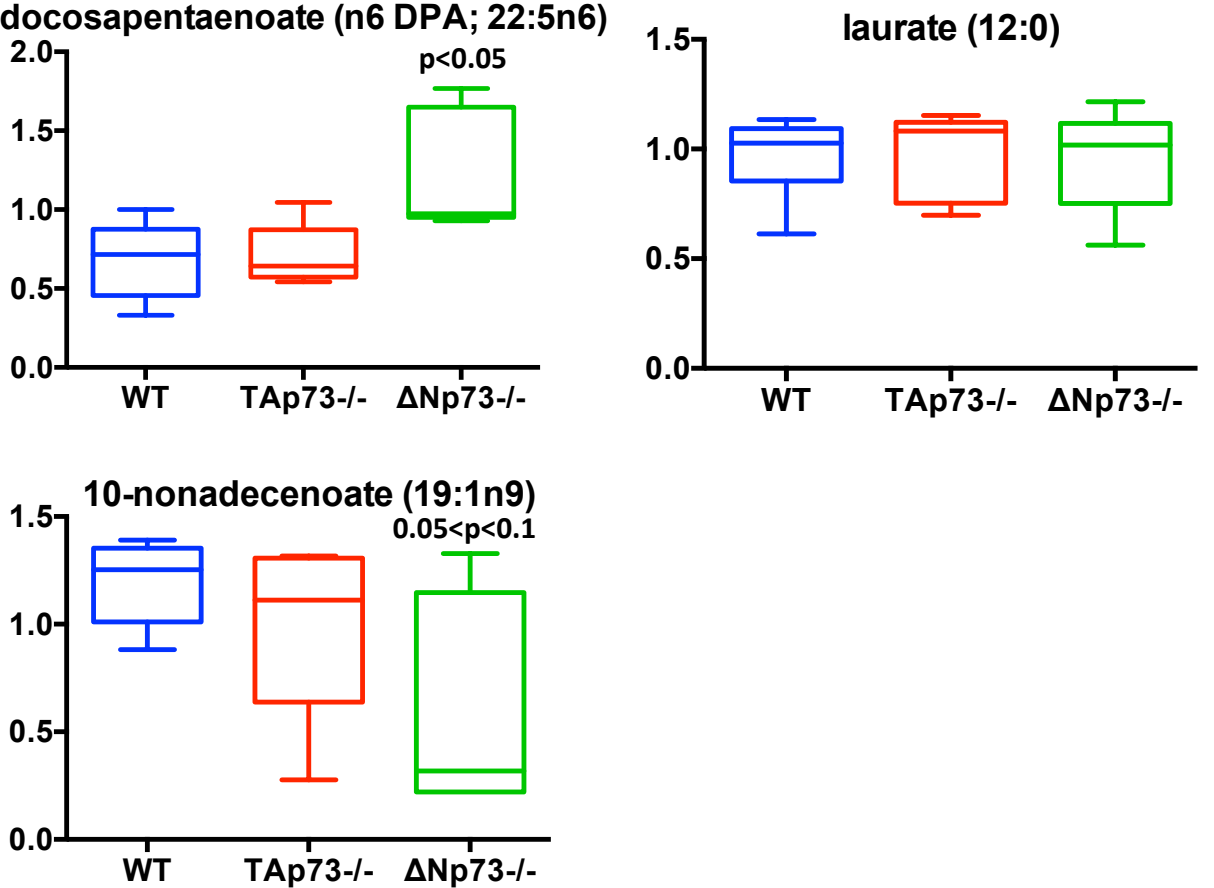
A
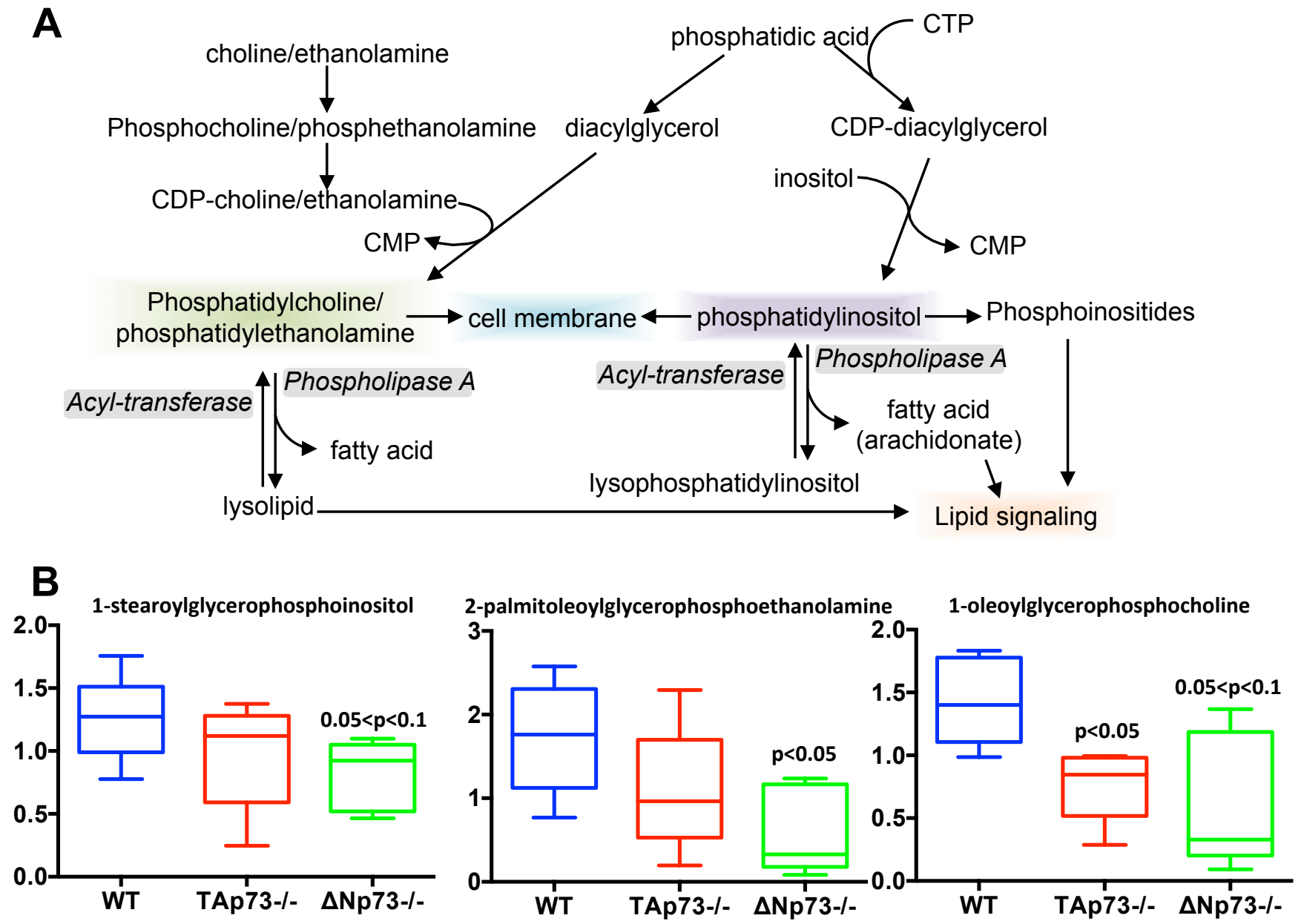
A
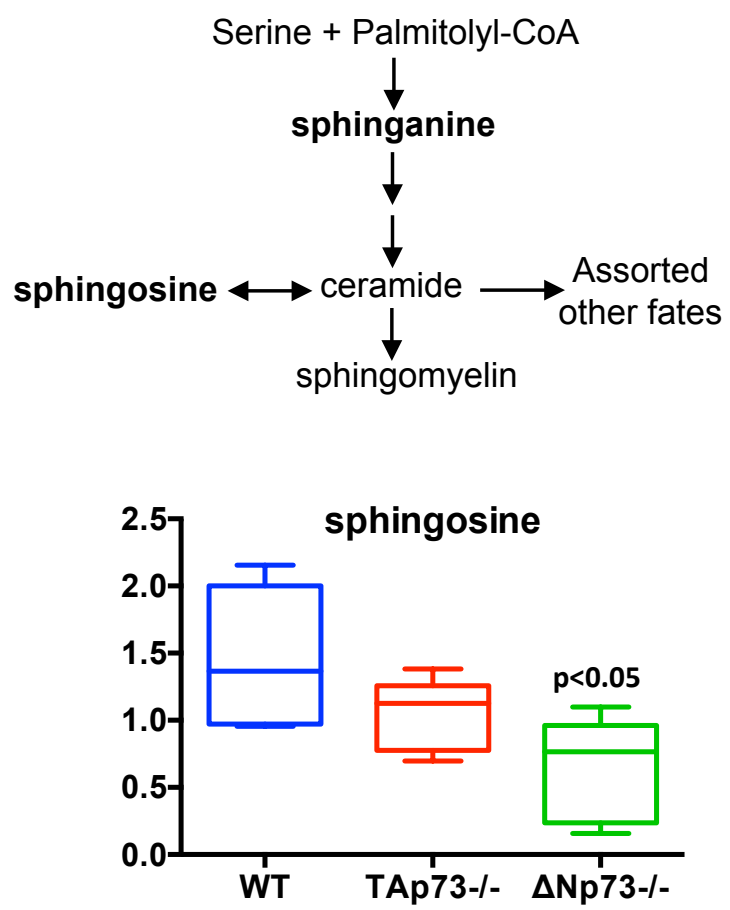

\section{B}
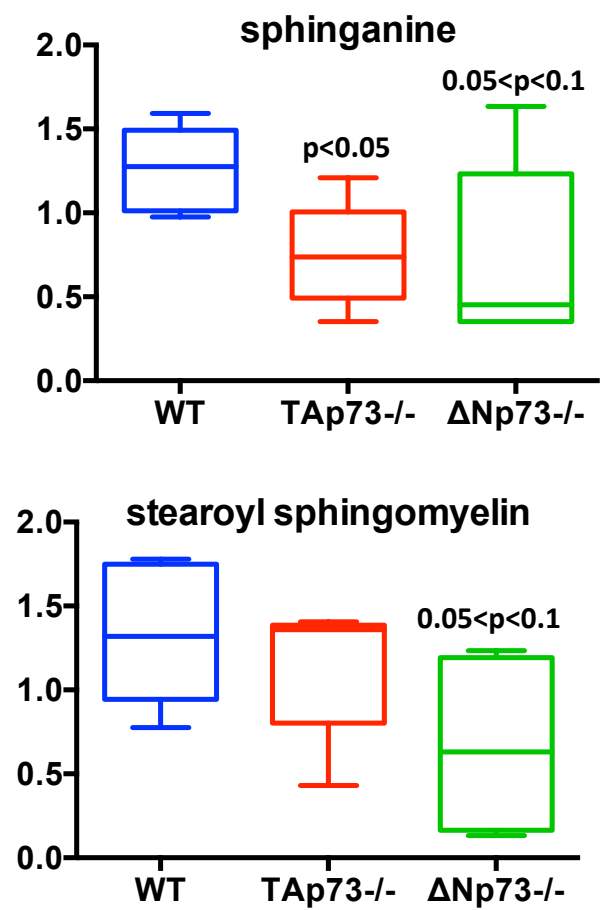

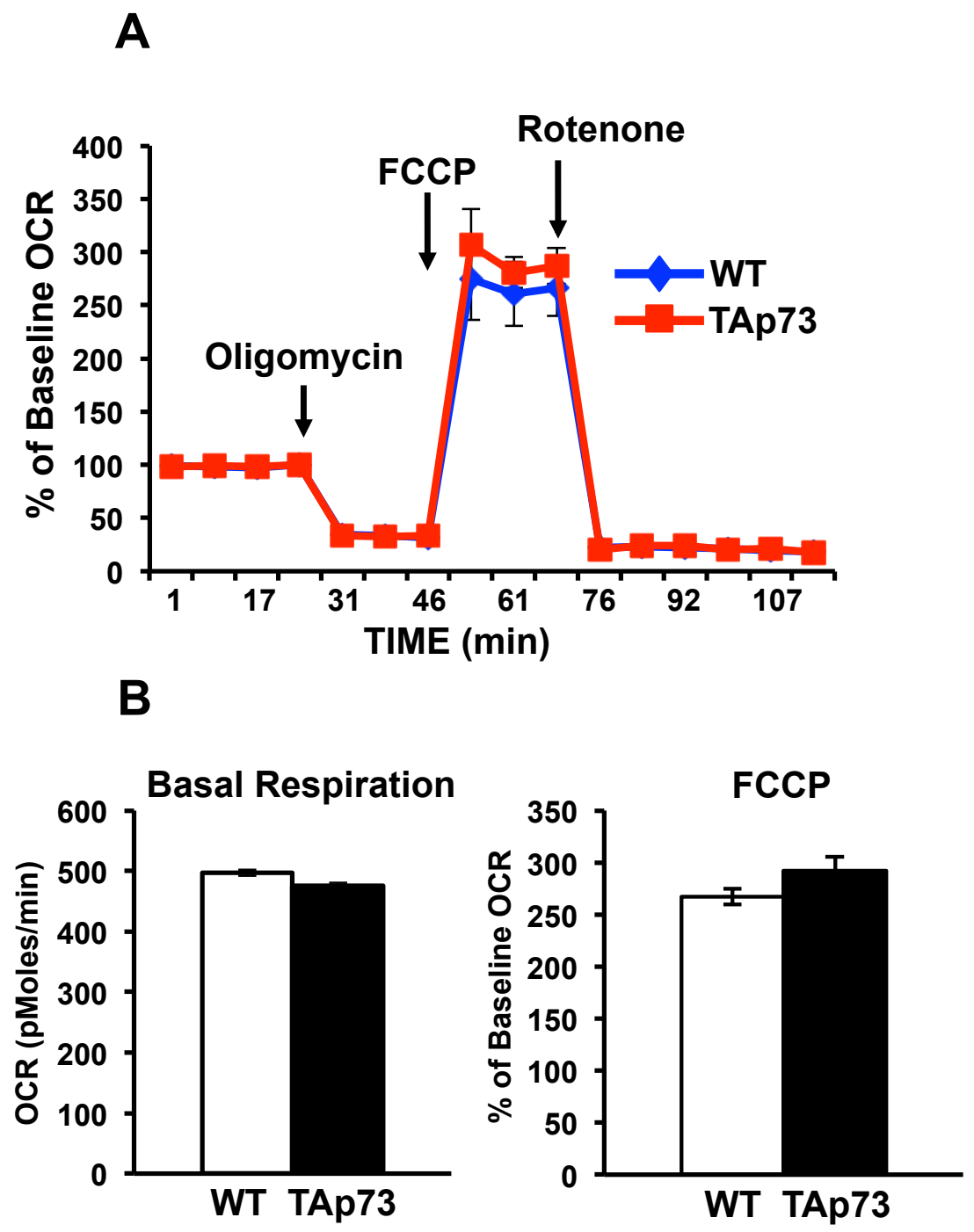

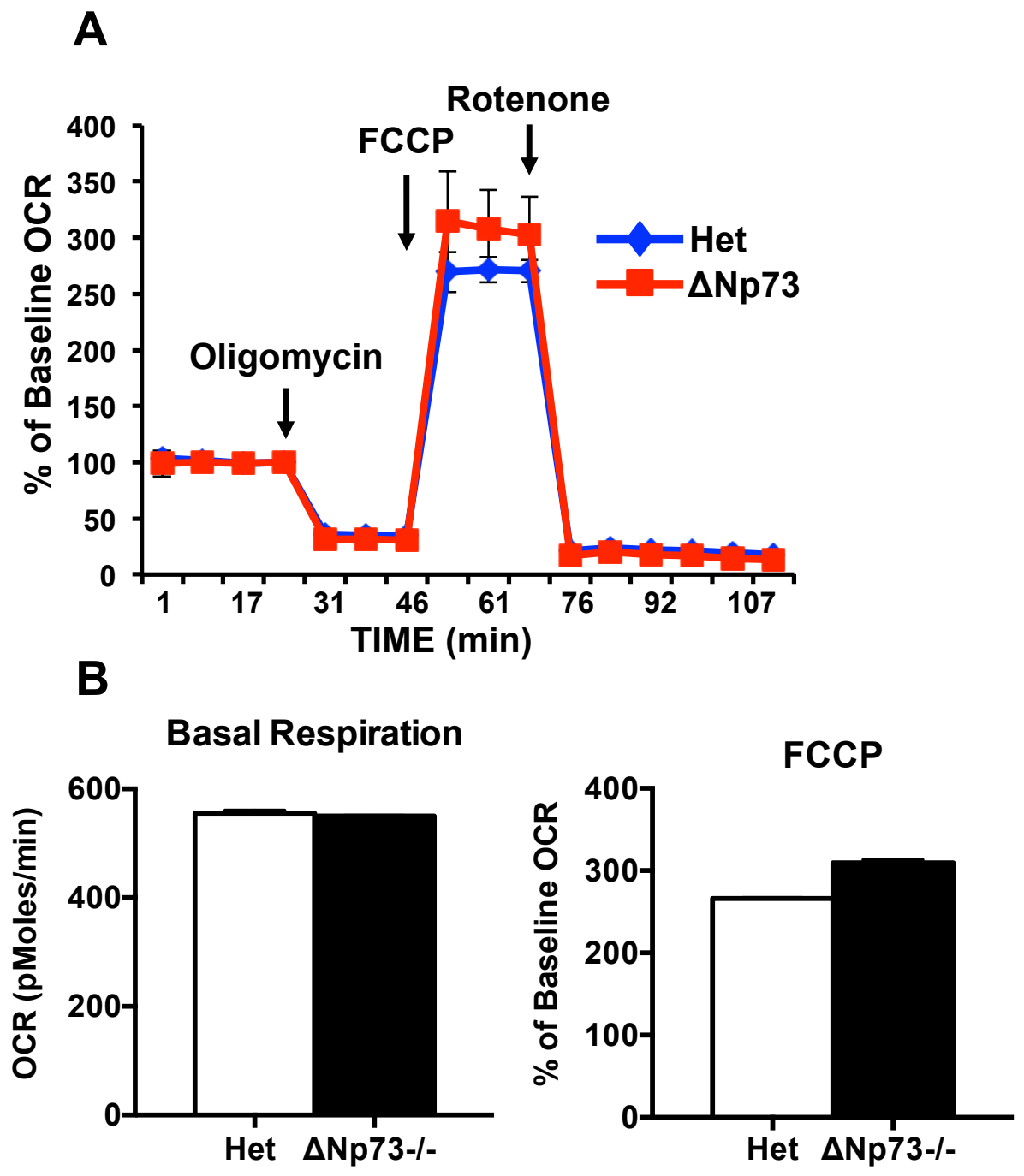


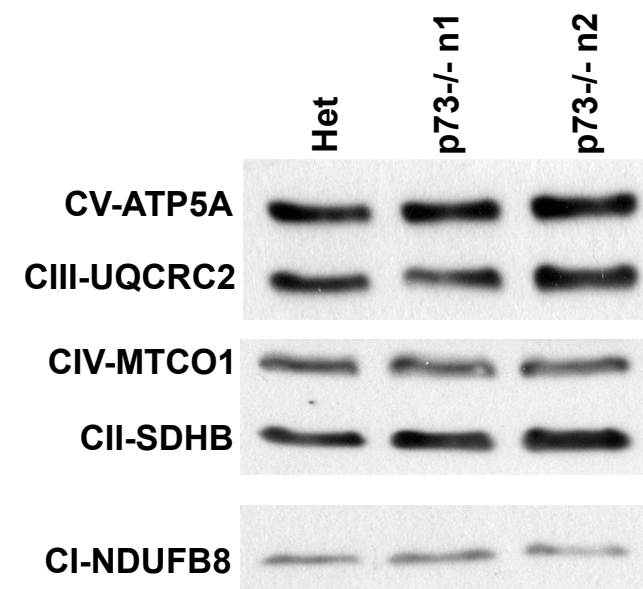

$\beta$-Tubulin

Agostini et al Figure S3 